\title{
CONSIDERAÇÕES SOBRE O ELEMENTO OBJETIVO DA LESÃO CONTRATUAL NO CÓDIGO CIVIL DE 2002
}

\author{
CONSIDERATIONS ABOUT THE OBJECTIVE ELEMENT \\ OF THE CONTRACTUAL LESION IN THE 2002 CIVIL CODE
}

\author{
Adauto de Almeida Tomaszewski \\ Celito De Bona**
}

\begin{abstract}
Resumo: $O$ presente artigo tem por objetivo discorrer acerca do elemento objetivo do instituto da lesão contratual, esculpida no art. 157 do Código Civil de 2002. Trata-se de instituto não previsto no Código de 1916, mas restaurado no atual, embora seu ressurgimento não se deva a este. Não obstante possuir elementos subjetivos, apenas será analisado seu elemento objetivo, acerca da ponderação subjetiva sobre o quanto deve ser considerado uma manifesta desproporção entre as prestações opostas, chamando a atenção para a importante atuação do magistrado pelo seu agir prudencial.
\end{abstract}

Palavras-chave: Lesão Contratual. Elemento objetivo. Parâmetros. Agir prudencial.

\begin{abstract}
This article focuses on the objective element of the contractual lesion present in Art. 157 of the Civil Code from 2002. This instance is not included in the code of 1916, but it was reinserted in the current one, although its resurgence is not due to the latter. Despite its subjective elements, only its objective element will be analyzed, particularly the subjective weighing on what should be considered a clear disproportion between the opposite sides, drawing attention to the magistrate's important performance by means of his prudence act.
\end{abstract}

Key-words: Contractual lesion. Objective element. Parameters. Prudence Act.

Mestre em Direito Negocial pela Universidade Estadual de Londrina/PR; Doutor em Direito Pela PUC/SP; professor dos cursos de Graduação, Especialização e Mestrado em Direito na UEL; professor dos cursos de Graduação e Especialização em Direito da PUC/PR - Campus Londrina/PR; professor do Curso de Mestrado em Direito Processual e Cidadania da UNIPAR - Campus sede Umuarama/PR; autor de diversas obras e artigos jurídicos. Email: adauto@uel.br

Especialista lato sensu em Direito Civil e Processual Civil pela Universidade Paranaense - UNIPAR/Toledo; especialista lato sensu em Filosofia do Direito pela Universidade Estadual do Oeste do Paraná - UNIOESTE; mestre em Direito Negocial pela Universidade Estadual de Londrina - UEL; professor da graduação em Direito no Centro Universitário Luterano de Ji-Paraná/RO - CEULJI - ULBRA. Email: celitodebona@yahoo.com.br 


\section{INTRODUÇÃO}

O Código Civil (Lei n. 10.406/2002) restaurou o instituto da Lesão Contratual no seu art. 157 como um defeito do Negócio Jurídico, na Parte Geral, Livro II, Título I, e Capítulo IV, por influir na vontade do contraente em celebrar o contrato, que fora suprimido pelo Código de 1916. Atribuída pelo legislador como defeito negócio jurídico, a lesão está no mesmo capítulo dos vícios do consentimento (dolo, erro e coação) e de um vício social (a fraude contra credores, visto que a simulação, também considerada um vício social, apresenta uma sanção diferente). A redação do artigo com seus dois parágrafos foi assim determinada:

Art. 157. Ocorre a lesão quando uma pessoa, sob premente necessidade, ou por inexperiência, se obriga a prestação manifestamente desproporcional ao valor da prestação oposta.

$\S 1^{\circ}$ Aprecia-se a desproporção das prestações segundo os valores vigentes ao tempo em que foi celebrado o negócio jurídico.

$\S 2^{\underline{0}}$ Não se decretará a anulação do negócio, se for oferecido suplemento suficiente, ou se a parte favorecida concordar com a redução do proveito.

De acordo com este artigo, lesão é o vício de consentimento do contraente na celebração de um negócio jurídico motivado por ocasião de uma premente necessidade ou inexperiência em que lhe obriga a uma prestação manifestamente desproporcional ao valor da prestação oposta, acarretando-lhe prejuízo, e que torna o contrato rescindível se não modificado a um razoável equilíbrio obrigacional entre as partes. Segundo Roberto Senise Lisboa, "lesão é a obtenção de vantagem indevida, em virtude da situação de inexperiência ou premência da vítima, acarretando-lhe prejuízo material” (LISBOA, 2009, p. 397).

A lesão configura, no direito atual, uma instituição destinada a salvaguardar a concorrência ao mercado e a mantê-la em condições de relativa e razoável paridade. Não se encontra neste estado quem está posicionado frente a outra parte de um negócio jurídico em estado de inferioridade, seja ela técnica ou financeira, ainda que momentaneamente.

Diante da disposição do art. 157 do Código Civil, se denota que sua cabeça é formada por dois elementos: um objetivo e outro subjetivo. O primeiro se constitui pela prestação manifestamente desproporcional ao valor da prestação oposta. A problemática reside em quanto deve ser esta proporção, visto que o texto do Código não dispôs de um limite ou tarifação para a configuração da lesão. Ademais, a diferença entre a lesão e o lucro, que não é proibido, poderá depender, a priori, da ótica pela qual se analisa a questão.

O elemento subjetivo é constituído ou pela premente necessidade suportada 
pelo contraente ou por sua inexperiência. O que vem a ser tanto uma ou outra deve ser analisado pelo juiz pormenorizadamente em cada caso em concreto, considerados os fatores sociais locais e a espécie e natureza de contrato, tudo de acordo com o seu agir prudencial, como apregoa o jurista Rodolfo Luis Vigo (2005).

Contudo, será que são necessários parâmetros para a utilização nesta atividade judicial, de modo a que haja uma uniformidade e coerência jurisprudencial, evitando-se uma possível insegurança ou incerteza jurídica? ${ }^{1} \mathrm{E}$ esta insegurança jurídica não é erroneamente tecida devida por ocasião do aparecimento das cláusulas gerais e conceitos legais indeterminados? Afastando neste trabalho a análise dos elementos subjetivos, não por não ser considerado relevante, mas por mera adequação ao espaço disponível para publicação, focalizar-se-á a atenção ao problema da delimitação do elemento objetivo, qual seja, indagarse-á quanto deverá ser considerada a lesão em termos proporcionais ao negócio jurídico celebrado. Eis a problemática maior do presente artigo.

\section{DO ELEMENTO OBJETIVO}

A prestação manifestamente desproporcional ao valor da prestação oposta, expressão utilizada pela cabeça do art. 157 do Código Civil, é uma afronta objetiva ao princípio da justiça contratual, em que se preza um equilíbrio entre as prestações cabíveis a cada contraente.

$\mathrm{Na}$ análise deste elemento objetivo, serão abordados os seguintes pontos:

a) o valor da prestação oposta;

b) a manifesta desproporção das prestações;

c) a ideia de lucro.

${ }^{1}$ Wilhelm Sauer afirma, em relação ao Direito, que a segurança jurídica é a finalidade próxima, enquanto a justiça é a finalidade distante (apud NADER, 1995, p. 139). Para Elías Días, a segurança não é só um fato, é também, sobretudo, um valor (apud NADER, 1995, p. 140). "Os conceitos de segurança jurídica e de certeza jurídica não se confundem. Enquanto o primeiro é de caráter objetivo e se manifesta concretamente através de um Direito definido que reúne algumas qualidades, a certeza jurídica expressa o estado de conhecimento da ordem jurídica pelas pessoas. Pode-se dizer, de outro lado, que a segurança jurídica possui um duplo aspecto: objetivo e subjetivo. $\mathrm{O}$ primeiro corresponde às qualidades necessárias à ordem jurídica e já definidas, enquanto o subjetivo consiste na ausência de dúvida ou de temor no espírito dos indivíduos quanto à proteção jurídica” (NADER, 1995, p. 140). 


\section{O VALOR DA PRESTAÇÃO OPOSTA}

$\mathrm{Na}$ análise do elemento objetivo, o primeiro ponto a se abordar é a exata compreensão do que seja o valor da prestação oposta, eis que se trata do ponto referencial deste elemento. No direito canônico, Santo Tomás de Aquino trouxe a noção de justo preço. Não se pode apresentar esta alternativa como solução ao problema, visto a enorme dificuldade de se conciliar uma definição do que seja considerado justo, eis que implicará sempre numa análise extremamente subjetiva acerca de sua definição e a existência de várias teorias sobre a justiça, em que pese ser esta a tendência atual do Direito, tal como se compreende do movimento denominado de pós-positivismo.

Alheio a esta distinção apresentada por Santo Tomás de Aquino, Roberto Senise Lisboa traz o preço justo (pretium iustum) como sendo:

[...] aquele proporcional ao valor da coisa, conforme o tempo e o lugar da celebração do negócio jurídico. É também chamado preço comum, pois resulta do intercambio econômico. É, portanto, preço não lesivo, não inferior à metade do preço comum (LISBOA, 2009, p. 400). ${ }^{2}$

Melhor alternativa se dá com o acolhimento do critério valor de mercado. Isto porque é relativamente fácil determinar o preço corrente, mas não o justo preço (da concepção tomista). De conseqüência, poderia o aplicador do direito ficar sem referência para determinar a ocorrência da lesão, e jamais o adquirente de boa-fé teria a certeza de que pagara o valor adequado pela coisa e, assim, se resguardaria contra a possibilidade de anulação do ato. É bem possível que o preço considerado justo não seja o de mercado, visto que a edificação de uma residência em determinado terreno pode gerar uma despesa muito maior do que o preço de mercado alcançado por ela considerando a conjuntura econômicofinanceira da época. Assim, se a construção teve um custo total de R $\$ 200.000,00$ (duzentos mil reais) e outros imóveis equivalentes são vendidos, pelo preço de mercado, a $\mathrm{R} \$ 120.000,00$ (cento e vinte mil reais), o que seria considerado justo, ou seja, os gastos com a construção, se adotado este critério, dificilmente o valor de mercado corresponderia ao ideal de Justiça. ${ }^{3}$

Para se obter o valor de mercado de certos bens, o magistrado encontra muita facilidade, por exemplo, ao se tratar de veículos automotores, com a

\footnotetext{
${ }^{2}$ Este mesmo autor difere o preço justo do preço legal e do preço verdadeiro, nestes termos: "Preço legal é aquele fixado em lei. Preço judicial é aquele determinado por decisão do Poder Judiciário. Preço verdadeiro (pretium verum) é aquele que genuinamente decorre da vontade humana séria e livre, e não de uma simples comparação de valores, como sucede com o preço justo" (LISBOA, 2009, p. 400-1).
} 
utilização da tabela Fipe. No caso de imóveis, a consulta a imobiliárias sobre negócios equivalentes efetuados na mesma época e praça, de preferência, dá um bom indício do valor de mercado desses bens. No caso de negócios com cereais, a consulta a cerealistas e armazéns da região também são um bom indicador do preço alcançado pelo produto no mercado numa delimitação de espaço e tempo. Se forem bens com cotação em bolsa, a simples constatação do valor do título no tempo da celebração do contrato bastará. Se houverem controvérsias pelas partes sobre o valor de mercado, não resta alternativa ao magistrado senão a designação de perícia. E isto se torna impossível com a adoção do critério do justo preço.

Além disso, o justo preço não é fixo, pois pode consistir na estimação de cada um, segundo a utilidade que retira do bem. E isto porque a partir do século XVI a sua concepção se deformou numa tricotomia de máximo, médio e ínfimo, sendo que somente o último servia de base à rescisão.

Não obstante a isso, com o novo Código Civil houve uma mudança axiológica implantando uma tendência de equilíbrio contratual entre as partes, ao menos é o uqe se visa, na medida do possível. É conveniente a passagem dos ensinamentos de Pablo Stolze Gagliano e Rodolfo Pamplona Filho, que aduzem:

Analisando ainda o art. 157, pode-se concluir ter havido uma verdadeira mudança axiológica no novo Código Civil, presente este vício de consentimento como verdadeira limitação à autonomia individual da vontade, não mais admitindo o "negócio da China", uma vez que não se aceitará mais passivamente a ocorrência de negócios jurídicos com prestações manifestamente desproporcionais (GAGLIANO; PAMPLONA FILHO, 2003, p. 376).

Concordando com os doutrinadores baianos, Flávio Tartuce complementa:

Entendemos que a lesão está configurada na prática do truck system, hipótese em que o empregador coloca à disposição do empregado mercadorias, no próprio local de trabalho, com preços bem superiores aos praticados no mercado. Essa prática, aliás, é vedada expressamente pelo art. 462, $\S \S 2^{\circ}$ a $4^{\circ}$, da CLT (TARTUCE, 2008, p. 366).

Não se deve olvidar ainda que o Estado nacional tem por base uma economia de mercado e com forte dirigismo estatal orientado à constituição de uma sociedade livre, justa e solidária, princípios estes implantados na Constituição Federal em seu art. $3^{\circ}$, inciso I, dentre outros objetivos. Exigir o preço corrente e não o justo se mostra mais adequado à orientação do ordenamento jurídico, vez que se pode dar referência ao julgador e dar eficácia ao art. 157 do Código Civil.

${ }^{3}$ Mais uma vez se afirma a enorme dificuldade em defini-la, ante aos vários sistemas de Justiça possíveis de serem adotados. 
Contudo, a adoção do critério do preço de mercado deve se ater a dentro de certos limites, pois o mercado pode (mas nem sempre) determinar o preço justo, do qual o valor corrente é apenas um indicativo. Assim, se pressupõe uma situação mercadológica convenientemente equilibrada. É possível que em razão de uma grande escassez de produtos, ou em virtude de monopólios ou oligopólios, ou mesmo de formação de cartéis, por exemplo, haja uma perturbação do equilíbrio econômico e o preço de mercado se encontre "maculado". Neste caso, além da necessária intervenção estatal para a restauração do equilíbrio, a adoção do preço de mercado deve ser refutada em benefício do lesado e utilizando como critério o valor estimado no mercado se não fosse aquele desequilíbrio e na medida de sua possibilidade. Observe-se que se este desequilíbrio decorrer de causas naturais, ou mesmo de força maior ou caso fortuito, também deverá ser considerado na apreciação judicial.

Não obstante a isso, dependendo do bem e da situação de equilíbrio econômico que se encontra é absolutamente aceitável algumas flutuações razoáveis em relação ao valor de mercado, eis que não raras vezes não se pode chegar a um limite ou preço certo. Tolera-se, assim, razoável margem de erro na determinação do preço de mercado e isso já impõe, por si só, a aceitação de razoáveis diferenças, na medida do possível. Desta forma, nem toda desproporção interessa ao Direito e nem qualquer divergência de valor entre os bens de mesma natureza ou equivalentes acarreta a lesão. É o que se verificará no próximo tópico.

\section{A MANIFESTA DESPROPORÇÃO DAS PRESTAÇÕES}

Não é sem razão que a cabeça do art. 157 do Código Civil traz o termo manifestamente. Segundo a versão eletrônica do Dicionário Aurélio, o adjetivo manifesto indica ser sinônimo de patente, claro, evidente, notório, flagrante. Isto porque a simples desproporção já é intrínseca a qualquer dinamicidade negocial, fazendo parte do sistema capitalista.

A problemática reside em quanto deve ser esta proporção, visto que o texto do Código Civil não dispôs de um limite para a configuração da lesão, isto é, não a tarifou. Aliás, os Códigos Civis contemporâneos, que instituíram a Lesão Contratual se dividem quanto à utilização de uma tarifação ou não.

Daqueles que utilizam a tarifação para a ocorrência da lesão se destacam a França, ${ }^{4}$ com 7/12 (sétima parte de doze ou sete doze avos), a Espanha, com a quarta parte $(25 \%),{ }^{5}$ e Itália, ${ }^{6}$ Chile $^{7}$ e Bolívia, ${ }^{8}$ assim como as antigas Ordenações Portuguesas, todos com inspiração no direito romano e canônico, que adotaram o critério lesivo como sendo o excedente da metade (50\%) do 
“justo preço”. No Brasil, a Lei de Economia Popular (Lei n. 1521/51)9 adotou a tarifação de $20 \%$ (vinte por cento), quebrando a tradição histórica do instituto.

Além disso, o próprio Código Civil de 2002 apresenta um caso de instrumento de manutenção do equilíbrio econômico (embora não se trate de espécie de lesão), aplicada aos contratos de empreitada, cuja tarifação deva ocorrer acima de dez por cento para a garantia do equilíbrio entre as prestações. É o que dispõe o art. 620: "Se ocorrer diminuição no preço do material ou da mão-de-obra superior a um décimo do preço global convencionado, poderá este ser revisto, a pedido do dono da obra, para que se lhe assegure a diferença apurada.”

O Brasil, seguindo países como Alemanha, Áustria, Polônia, Argentina, Paraguai e México, não adotou a tarifação, optando em deixar a constatação para cada caso, de acordo com os critérios do juiz nos casos específicos.

${ }^{4}$ Código Civil Francês - Article 1674: Si le vendeur a été lésé de plus de sept douzièmes dans le prix d'un immeuble, il a le droit de demander la rescision de la vente, quand même il aurait expressément renoncé dans le contrat à la faculté de demander cette rescision, et qu'il aurait déclaré donner la plus-value.

${ }^{5}$ Código Civil Espanhol - Art. 1.291. Son rescindibles:

$1^{\circ}$. Los contratos que pudieren celebrar los tutores sin autorización judicial, siempre que las personas a quienes representan hayan sufrido lesión en más de la cuarta parte del valor de las cosas que hubieren sido objeto de aquéllos.

${ }^{6}$ Código Civil Italiano - Art. 1448 Azione generale di rescissione per lesione [...]. L'azione non è ammissibile se la lesione non eccede la metà del valore che la prestazione eseguita o promessa dalla parte danneggiata aveva al tempo del contratto.

${ }^{7}$ Código Civil Chileno - Art. 1889. El vendedor sufre lesión enorme, cuando el precio que recibe es inferior a la mitad del justo precio de la cosa que vende; y el comprador a su vez sufre lesión enorme, cuando el justo precio de la cosa que compra es inferior a la mitad del precio que paga por ella.

${ }^{8}$ Código Civil Boliviano - Art. 561.- (RECISION DEL CONTRATO POR EFECTO DE LA LESION).

I. A demanda de la parte perjudicada es rescindible el contrato en el cual sea manifiestamente desproporcionada la diferencia entre la prestación de dicha parte y la contra-prestación de la otra, siempre que la lesión resultare de haberse explotado las necesidades apremiantes, la ligereza o la ignorancia de la parte perjudicada.

II. La acción rescisoria sólo será admisible si la lesión excede a la mitad del valor de la prestación ejecutada o prometida. (Arts. 413, 563, 1277, 1278 del Código Civil).

${ }^{9}$ Lei $1521 / 51$ - Art. $4 \stackrel{\circ}{ }$. Constitui crime da mesma natureza a usura pecuniária ou real, assim se considerando:

a) cobrar juros, comissões ou descontos percentuais, sobre dívidas em dinheiro superiores à taxa permitida por lei; cobrar ágio superior à taxa oficial de câmbio, sobre quantia permutada por moeda estrangeira; ou, ainda, emprestar sob penhor que seja privativo de instituição oficial de crédito;

b) obter, ou estipular, em qualquer contrato, abusando da premente necessidade, inexperiência ou leviandade de outra parte, lucro patrimonial que exceda o quinto do valor corrente ou justo da prestação feita ou prometida. 
Tanto a tarifação como a discricionariedade judicial possuem vantagens e desvantagens. Em relação à tarifação, seu ponto positivo é a facilidade em que o magistrado encontra para a constatação da lesão, num legítimo aspecto de segurança jurídica, não dando azo para a voluntariedade e arbítrio dos juízes, visto que nem todos possuem a sensatez e a prudência necessária em seu agir decisório devido ao desconhecimento do tema ou pela análise superficial do processo. ${ }^{10}$ Também não gera interpretações divergentes ou conflitantes, criando incertezas jurisprudenciais. O jurista italiano Roberto de Ruggiero afirma que:

Árdua e delicada é a missão do legislador ao determinar até que ponto o livre arbítrio do indivíduo, ao medir a equivalência das prestações foi superado pela inexperiência, pelas necessidades urgentes ou por outras causas perturbadoras, de modo que, faltando qualquer correspondência, se imponha um remédio legal a favor do contraente lesado, visto que ou se adota um limite predeterminado e se corre o risco de deixar sem tutela uma série de convenções lesivas, ou não se adota um limite fixo e admite-se a impugnabilidade por lesão cada vez que há uma grave desproporção, e então corre-se o outro perigo de expor as convenções a impugnações caprichosas e arbitrárias (RUGGIERO, 1971, p. 276).

Entretanto, por se tratar de mero arbítrio do legislador, com base em concepções provavelmente conjunturais sócio-econômicas, engessa a prática dos tribunais. Fundamentado num critério rígido, não autoriza a reprovação de negócios que tenham alcançado muito próximo do limite legal fixado, sem configurar a lesão. É um facilitador da conduta de agentes inescrupulosos e de má-fé, que não terão a dificuldade de se proteger da intervenção judicial ao estipular avenças flagrantemente abusivas, mas dentro dos padrões mínimos estipulados legalmente. Caio Mário da Silva Pereira tece a seguinte crítica à tarifação: "É que qualquer tarifa seria arbitrária, com o inconveniente da inflexibilidade. Um contrato, cujo desequilíbrio de prestações seja evidente, deve suportar a impugnação por lesão” (PEREIRA, 1994, p. 188).

Uma regra rígida que o juiz deve aplicar sem reflexões ou ponderações não é, por certo, o que exige uma sociedade dinâmica, em constante evolução cujo arcabouço jurídico deve se flexibilizar frente às novas circunstâncias não previstas pelo legislador. As cláusulas gerais e os conceitos legais indeterminados tornam-se as chaves de abertura do claustro em que se encontra o ordenamento jurídico. Ao utilizar a tarifação ou tabelamento o legislador retroagiria na escala

${ }^{10}$ Considerando-se o fato de que tanto os juízes de primeiro grau como os tribunais estão com excessos de processos e uma análise minuciosa em cada caso exigiria uma atenção e dedicação sobre-humana, muito mais próxima e condizente do juizpersonagem Hércules, de Ronald Dworkin (2002), em sua obra Levando os direitos a sério. 
evolutiva do Direito Civil e das técnicas legislativas, o que não se mostra mais adequado e eficaz, ao contrário, faz com que o juiz não puna o ardil utilizado pelo contraente de má-fé. Como defende Anelize Becker:

$\mathrm{O}$ emprego de conceitos indeterminados mostra-se, portanto, muito mais eficaz e adequado para uma valorização realista do caso concreto, na medida em que possibilita ao juiz verificar a gravidade da desproporção da forma mais consentânea possível com as circunstâncias concretas (BECKER, 2000, p. 113-4).

Pelo que se percebe, a sistemática da tarifação é mais adequada aos ordenamentos que possuem o requisito puramente objetivo. Tal rigidez parece ser válida quando há segurança nas transações que não são influenciadas pelos elementos subjetivos, como a premente necessidade ou a inexperiência do contraente que, se a tivesse, não contrairia o negócio. Neste sentido, Vladimir Mucury Cardoso defende:

A exigibilidade do segundo requisito [subjetivo], a nosso ver, afasta a insegurança que poderia advir da ausência de taxa preestabelecida, uma vez que não é mais a pura desproporção suficiente para invalidar o ato. Assim, passa a ser possível sopesar as circunstâncias concretas, de modo a apreciar se, em cada caso, o desequilíbrio porventura existente é ou não suficiente para configurar a lesão (CARDOSO, 2008, p. 208).

Mas então, se a conclusão é no sentido de que o melhor sistema é o da indeterminação do conceito, ou seja, sem a tarifação, o que se poderá entender como prestação manifestamente desproporcional ao valor da prestação oposta, elemento objetivo que constitui a lesão? Qual a sua mensuração?

Adauto de Almeida Tomaszewski defende a adoção de um patamar em torno de $50 \%$ a $60 \%$, e explica com o seguinte exemplo:

[...] se nas mesmas condições, adquiriu um bem por preço que exceda, em 50\% o seu valor, de igual maneira deveria incidir a norma do artigo 157 do Código Civil. Por intermédio deste raciocínio, se um indivíduo " $\mathrm{A}$ " aliena bem seu, sob os requisitos da aludida norma, por $\mathrm{R} \$ 50.000,00$ mas o valor deste supera $\mathrm{R} \$ 100.000,00$, ou, se adquire por valor superior a $\mathrm{R} \$ 75.000,00$ um bem cujo valor somente alcança $R \$ 50.000,00$, então a lesão está de plano configurada e sob patamares razoáveis. Aliás, por falar em razoabilidade, é este mesmo raciocínio que deve nortear o operador do Direito, se os valores mencionados a título de exemplo oscilarem para um pouco a mais ou para um pouco a menos (TOMASZEWSKI, 2005, p. 15; grifo nosso).

Já Roberto Senise Lisboa afirma que:

A falta de parâmetro no novo Código Civil impede que se considere tal percentual como fórmula absoluta. Saliente-se ainda que a lei de crimes contra a economia popular considera desproporcional a prestação que excede em um quinto $(20 \%)$ do valor do bem oferecido. O percentual estabelecido por essa lei 
pode ser adotado pelo juiz ao analisar o caso concreto, mediante a aplicação da analogia (LISBOA, 2009, p. 401). ${ }^{11}$

Não obstante a este entendimento, aqui se defende que deverá ser considerado como elemento objetivo todo aquele desequilíbrio induvidoso e inquestionável, em que a disparidade entre as prestações é injustificável, revelando-se inaceitável segundo os ditames da equidade, não se optando pela adoção de um patamar certo, pois que seria o mesmo que tarifar o elemento objetivo. $O$ jurista argentino Santos Cifuentes assevera que:

A vantagem obtida deve ser evidente, no sentido de demonstrativa de uma grande diferença que não deixe margem de dúvidas. Além disso, há que ser, também, injustificada, ou seja, desprovida de um motivo verdadeiro, como, por exemplo, um grande valor afetivo que tenha feito com que a suposta vítima admitisse pagar um preço desproporcionado (apud CARDOSO, 2008, p. 210).

Para Caio Mário da Silva Pereira será apurado objetivamente a lesão "na desproporção evidente e anormal das prestações, quando um dos contratantes aufere ou tem possibilidade de auferir do contrato um lucro desabusadamente maior do que a contraprestação que se obrigou” (PEREIRA, 1994, p. 187).

Sustenta-se a ideia de que o juiz, ao analisar o elemento objetivo no caso concreto, ante a ausência de tarifação, deve colocar toda a sua experiência e agir com prudência inerente à nobre função que exerce. Neste ponto é forçoso pedir auxílio a Rodolfo Luís Vigo, que defende que a prudência jurídica possui duas dimensões, sendo uma cognitiva (de deliberação e de juízo de eleição) e outra preceptiva, e tem como objeto deliberar sobre as condutas jurídicas possíveis e julgar qual é a preferida. Para ele,

a interpretação da lei será um esforço metódico da razão prática em nível prudencial, tendo por finalidade determinar, em certas circunstâncias e a partir do seu texto e demais elementos do ordenamento jurídico, um 'seu' de alguém, dando as razões e argumentos que permitam respaldar e fundar a conclusão a que se chegou (VIGO, 2005, p. 109).

Este mesmo jurista entende que

Optar pela natureza prudencial do raciocínio jurídico interpretativo nos protege de certo relativismo em que incorrem aqueles que contemporaneamente recorrem exclusivamente à retórica. A prudência implica a superação das explicações meramente racionais, ao modo de Savigny ou da "jurisprudência de conceitos", ou das exclusivamente voluntaristas como as de Kelsen. Além disso, também previne contra o risco de incorrer num historicismo destruidor do permanente

${ }^{11}$ De observar que este autor acaba entrando em contradição com aquilo defendido anteriormente acerca do preço justo, quando diz: "É, portanto, preço não lesivo, não inferior à metade do preço comum” (LISBOA, 2009, p. 400). 
ou num imobilismo que nos faça esquecer o contingente e o mutável, como também destaca o individual ou o particular, mas sem marginalizar o geral ou o arquitetônico. Por fim, igualmente possibilita a autonomia do jurídico sem cair em juridicismos que desumanizam, confiando além disso na informação jurídica, sem deixar de destacar a importância fundamental da experiência. E o retórico implica a necessidade de mostrar a razoabilidade e justiça da determinação jurídica na conclusão do silogismo prudencial com a finalidade de persuadir seus destinatários. Ter presente dita arte da palavra e da controvérsia se vincula a uma certa humanização do direito, exigindo razões de quem exige, aconselha ou ensina, para assim conseguir que se respeite o outro no 'seu' (suum) por meio da persuasão e não somente da ameaça. Para que a deliberação desemboque fácil e corretamente no juízo de escolha, depois de valorar devidamente as diferentes alternativas e confrontar as diversas fundamentações, deve fincar o seu fundamento na arte da polêmica e da persuasão (VIGO, 2005, p. 122).

Não se pode negar que os conceitos abertos ou as cláusulas gerais estão vinculadas a uma força normativo-axiológica aplicável ao direito (ordenamento jurídico) pelo intérprete-juiz, constitui-se de uma busca na recuperação dos princípios do direito aplicáveis ao que Dworkin denomina de hard cases ou aos "casos difíceis".

Assim, quando se depara com um caso de difícil solução, como é a interpretação do elemento objetivo da lesão contratual, que dependerá de cada caso concreto, o intérprete-juiz poderá utilizar critérios extra-jurídicos para resolvê-lo. Todavia, quando desta forma age, utilizando outros métodos que não os especificamente previstos pelo direito, não está aplicando este, mas está "inventando" o direito de certo modo. Noutras palavras, está ultrapassando os limites do Direito - a lei como sua fonte - dentro de uma concepção positivista de Hart, pois sua regra de reconhecimento se constrói precisamente para identificar o direito.

Esta função criativa/criadora no/do Direito é defendida por jusfilósofos do quilate de Luís Recaséns Siches que em sua teoria sobre lógica do razoável diz:

A lógica do humano ou do razoável é uma razão impregnada de pontos de vista estimativos, de critérios de valoração, de pautas axiológicas, que ademais trazem consigo a organização dos ensinamentos recebidos da experiência própria ou da experiência do próximo através da história. (RECASÉNS SICHES, 1975, p. $642) .{ }^{12}$

Assim, no que tange ao julgar, este é fruto de estimativa, pois para o juiz

${ }^{12}$ La lógica de lo humano o de lo razonable es una razón impregnada de puntos de vista estimativos, de critérios de valoración, de pautas axiológicas, que además lleva a sus espaldas como allenacionamiento las ensinanzas recibidas de la experiencia, de la experiencia propria o de la experiencia del próximo através de la historia. 
chegar à intuição sobre a justiçẩ ${ }^{13}$ do caso concreto (ou, se preferir, à menor injustiça, dependendo o caso) não separa sua opinião sobre os fatos das dimensões jurídicas desses mesmos fatos. Tomaszewski complementa que:

Isto faz com que a função do juiz, embora mantendo-se dentro da observância do Direito formalmente válido, seja sempre criadora, por alimentar-se de um amplo complexo de valorações particulares sobre o caso concreto. [...] Recaséns Siches explicava que a estimativa jurídica informa ao intérprete sobre quais são os valores cujo cumprimento deve ou não ser perseguido pelo Direito, tais como justiça, dignidade da pessoa humana, liberdades fundamentais do homem, segurança, ordem, bem-estar geral e paz. Entretanto existem outros que podem ser englobados no conceito do que tradicionalmente se denomina prudência, sensatez, equilíbrio, possibilidade de prever as conseqüências da aplicação da norma e sopesar entre vários interesses contrapostos, legitimidade dos meios empregados para atingir fins justos, etc. (TOMASZEWSKI, 2006, v. 2, p. 13). [...] Esta teoria, construída de forma compatível com todos os anseios de uma época, dá ao operador, principalmente ao julgador, uma atividade criadora, imbuindo-o do objetivo maior do Direito (TOMASZEWSKI, 2006, v. 2, p. 29). [...] Desta forma, a interpretação deve operar-se dentro de critérios de razoabilidade, de sorte que o Direito seja entendido com vistas à realidade, para atingir seu objetivo: regular comportamentos sociais. O Direito não deve se ocupar dos homens, mas da sua conduta (TOMASZEWSKI, 2006, v. 2, p. 30). (Grifos nosso).

Desta forma, se depreende duas considerações a tecer sobre esta análise do elemento objetivo. A primeira é que não se pode haver um parâmetro rígido para a configuração da lesão, como a metade (50\%), vinte por cento $(20 \%)$ ou vinte e cinco por cento (25\%), do valor a prestação oposta. Admite-se a extrema dificuldade de se apreender contornos para sua configuração. Dependerá sempre da natureza do negócio e do valor posto em questão. Imagine-se um veículo modelo fusca, marca Volkswagen, de ano de fabricação 1966, em péssimo estado de conservação. Se colecionadores pagarem por ele o preço de mercado no valor de $\mathrm{R} \$ 2.000,00$ (dois mil reais) e o proprietário o vender por $\mathrm{R} \$ 1.000,00$ (mil reais) à única pessoa interessada dentro de um período considerável de oferta nos classificados de periódico local, por exemplo, não se poderá afirmar que houve lesão, ainda que existente um elemento subjetivo. No máximo se poderá alegar que houve um mau negócio. Mas não dá ensejo à rescindibilidade da venda pela lesão.

Outro exemplo em que não se configura a lesão é o do adquirente que paga, ao adquirir uma carta de crédito recém contemplada de consórcio de automóveis, além das três parcelas que o alienante já havia pago, um ágio de

${ }^{13}$ E aqui se evita definir o que seja "justiça”, pois dependeria da análise e adoção de uma das várias teorias que tratam do assunto. Tem-se como justiça aquilo que o magistrado entenderá válido e aplicável no caso concreto. 
mais de 100\% (cem por cento) sobre elas para obter o benefício. Assim, se cada parcela corresponde a $\mathrm{R} \$ 400,00$ (quatrocentos reais) e ele pagar $\mathrm{R} \$ 2.500,00$, sabe que $\mathrm{R} \$ 1.300,00$ (mil e trezentos reais) referem-se a pagamento de ágio. Em contrapartida, recebe a vantagem de não esperar qualquer sorteio para somente ser contemplado no futuro e poder faturar logo o veículo.

Porém, se uma viúva já em idade avançada possuir um único imóvel, cujo valor de mercado é R\$ 1.000.000,00 (um milhão de reais), conforme se verifica em negócios realizados no mesmo período e com imóvel equivalentes, ou seja, de mesma localidade e nível de acabamento, e vender o imóvel por R $\$$ $600.000,00$ (seiscentos mil reais), o elemento objetivo da lesão se configura, pois se trata de uma evidente desproporção.

Importa, pois, uma evidente disparidade entre as prestações e que dependerá da natureza contratual e também dos valores que se discutem. $\mathrm{O}$ patamar poderá ser em torno de 50\% (cinqüenta por cento) ou mesmo 1/5 (um quinto), mas exige-se sempre o agir prudencial do magistrado e que motive sua decisão com base nisto e de acordo com a natureza do negócio. Uma venda de imóvel com uma desproporção de 15\% (quinze por cento) não pode ser considerada lesiva, mas a estipulação deste patamar em juros remuneratórios mensais num contrato de mútuo entre particulares (lesão usurária), sim.

Esta dificuldade no vislumbre dos contornos de sua configuração dependerá realmente da apreciação judicial e não se deve fazer alarde em relação a isto, como sendo algo monstruoso ou fora de qualquer conexão com a realidade. Numa atenta análise do cotidiano judicial, esta mesma tarefa ocorre diariamente nas varas cíveis com a configuração do dano moral e sua liquidação, visto que inexistem patamares certos, devendo a sensatez e prudência do magistrado substituir a sua tarifação. Quando do início da aplicação do dano moral nos tribunais pátrios, o alvoroço em torno da possível insegurança jurídica também deu azo a inúmeros debates que atualmente se encontram superados devido à prática atual.

O instituto da lesão, revigorado com o Código Civil de 2002, acredita-se, seguirá o mesmo caminho traçado pelo dano moral, a partir de seu estudo sistemático pela doutrina e por sua apreciação pelos tribunais pátrios. Daí a importância de seu estudo e domínio sobre o tema.

Não se pode, ainda, deixar de lembrar que a ausência de tarifação ou parâmetros rígidos na configuração do elemento objetivo está de acordo com as diretrizes do movimento pós-positivista e também com os mais modernos Códigos Civis e legislações de outros países que recepcionam o instituto da lesão. 
A segunda consideração é no sentido de que a manifesta desproporção na prestação, para que ocorra a lesão, não depende somente das principais prestações estipuladas no contrato, mas de todo o seu conjunto, inclusive das acessórias e também nos benefícios patrimoniais desmesurados, excessivos, ainda que as prestações em si possam parecer, em princípio, equilibradas. Assim, a lesão pode não estar localizada no preço propriamente dito, mas na concessão de um prazo exageradamente dilatado, na estipulação de penalidades demais rigorosas para uma das partes, etc. Daí o motivo do aplauso à redação do art. 282 do Código Civil de Portugal, ao se referir a "benefícios excessivos ou injustificados e não à tradicional expressão manifestamente desproporcional ao valor da prestação”. ${ }^{14}$

Destarte, observe-se o contido no art. 413 do Código Civil, ${ }^{15}$ em que o magistrado poderá reduzir equitativamente a cláusula penal "se a obrigação tiver sido cumprida em parte, ou se o seu montante for manifestamente excessivo, tendo-se em vista a natureza e a finalidade do negócio.”

Desta forma, no exemplo da viúva que vende seu móvel, se na análise das cláusulas contratuais houver alguma que justifique a diminuição do preço do imóvel, como um comodato ou usufruto vitalício em seu favor, para que habite o mesmo até sua morte, aliado a uma renda vitalícia significativa, ou a prestação de determinados serviços, o elemento objetivo da lesão pode ser afastado e, por conseguinte, sua própria configuração. Mas, ressalve-se, de acordo com a análise judicial das circunstâncias apresentadas.

Sílvio de Salvo Venosa menciona que o requisito objetivo se configura pelo lucro exagerado (2007, p. 413). É merecedora, todavia, uma explicação acerca da íntima relação entre lesão e lucro, pois este, pelo sistema capitalista, é não apenas lícito, mas a finalidade de qualquer atividade empresarial e não apresenta, em regra, limites, diante das práticas empresariais atuais. É o que será tratado no tópico seguinte.

\section{A IDÉIA DE LUCRO}

É mister também abordar neste artigo a questão da diferença entre a lesão num contrato e a aquisição de lucro, considerando não se olvidar do sistema

${ }^{14}$ Art. $282^{\circ}$ do Código Civil de Portugal: É anulável, por usura, o negócio jurídico, quando alguém, explorando a situação de necessidade, inexperiência, ligeireza, dependência, estado mental ou fraqueza de carácter de outrem, obtiver deste, para si ou para terceiro, a promessa ou a concessão de benefícios excessivos ou injustificados.

${ }^{15}$ Art. 413. A penalidade deve ser reduzida eqüitativamente pelo juiz se a obrigação principal tiver sido cumprida em parte, ou se o montante da penalidade for manifestamente excessivo, tendo-se em vista a natureza e a finalidade do negócio. 
capitalista que se impõe atualmente na nova ordem econômica mundial. A diferença entre a lesão e o lucro, que não é proibido, poderá depender da ótica pela qual se analisa a questão. Enquanto o lesado sente-se ofendido pelo prejuízo que teve com a celebração do suposto viciado negócio, a outra parte encontra nele uma atividade lucrativa, ainda mais em se tratando de atividade empresarial.

O lucro nada mais é do que aquilo que excede o valor de custo da mercadoria quando negociada. Como valor de custo da mercadoria se compreende todo aquele despendido na formação da mercadoria, como matéria prima, meios de produção (energia e equipamentos usados), força de trabalho (salários dos empregados), tributos e logística. Além disso, atualmente a gestão empresarial deve incorporar neste valor outros fatores que encarecem a mercadoria, como uma margem de previsão de inadimplência, seguros diversos e, em alguns casos, royalties devido a direitos autorais e intelectuais.

Aquilo que exceder este preço de custo da mercadoria ou serviço atualmente é considerado como lucro. Ressalte-se que, devido a não mais ampla influência da Igreja Católica, como ocorria nos tempos medievos, atualmente o lucro é algo normal e corriqueiro, senão imprescindível para a manutenção do sistema capitalista e o objetivo de toda atividade empresarial ou negocial.

Possui o lucro uma margem variável de cada produto considerada sua utilidade e também a proporcionalidade entre maior ou menor procura e oferta no mercado, que o regulará com vistas também na concorrência empresarial apresentada, seja interna (nacional) ou externa (estrangeira).

De observar que os economistas são praticamente unânimes ao afirmarem que, em regra, não existem limites ao lucro, mas não devem ser considerados exagerados ou exorbitantes, devendo guardar uma mínima proporcionalidade com a realidade social. Daí a importância da concorrência no mercado para regular e frear eventuais abusos cometidos nos mais variados setores da economia e a intervenção estatal por intermédio do dirigismo governamental.

Assim, é possível a existência de até mil por cento de lucro sobre o valor da mercadoria, sem que haja interferências governamentais, desde que inexista a formação de cartéis no setor ou alguma forma de desleal concorrência. Não é raro encontrar produtos de decoração em lojas de grifes vendidos por quase (ou mais de) $R \$ 1.000,00$ (mil reais) enquanto os mesmos produtos podem ser encontrados em lojas de artesanato ou lojas ditas "populares" por menos da décima parte deste valor. Não haverá, então, neste caso, a ocorrência de lesão contratual, visto se tratar de oferta pública de mercado, em que o consumidor poderia e deveria saber pesquisar melhor a escala de preços dos pretendidos produtos. Além disso, é comum que produtos adquiridos em shopping centers tenham preços mais elevados em razão da comodidade encontrada e proporcionada, como 
estacionamento facilitado, segurança privada, ar condicionado interno, ampla área de lazer, etc. Ademais, por se tratar de produtos de decoração, trata-se de despesas não essenciais, supérfluas, pomposas ou de ostentação, não guardando proporção com a premente necessidade de aquisição.

É bem verdade que o lucro não encontra, em princípio, limite, tanto que assim decidiu o Tribunal de Justiça do Paraná, em recente acórdão:

Diante da inexistência de limitação legal para o lucro da Instituição Financeira, a simples alegação de que o "Spread" foi superior a 20\% não é capaz de ensejar a configuração do desequilíbrio contratual, eis que o referido "Spread" é comparado ao "lucro bruto", logo, para se verificar o abuso deve-se demonstrar cabalmente que retirando-se os custos da captação permaneça, ainda, um lucro exagerado, fato este não demonstrado nos autos. (TJPR - 15ํㅡ. C.́ivel - AC 0536013-0 Paranavaí - Rel.: Des. Jucimar Novochadlo - Unanime - J. 26.11.2008).

Contudo, as práticas governamentais de intervenção na economia ocorrem sempre que se percebe um desequilíbrio nos setores essenciais ou mais importantes. Tais práticas, também chamadas de dirigismo estatal, interferem ou na área de tributação, aumentando ou diminuindo as alíquotas que incidem no setor, ou proibindo determinadas práticas empresariais, ou fomentando outras, com a concessão de créditos empresariais para a formação de concorrência no setor. Outras vezes consistem na concessão ou restrição de crédito ao consumo de determinados produtos ou serviços, sempre visando seu aperfeiçoamento ou diminuição de produção. Esta interferência funciona como uma orquestra, cujo maestro, o Estado, deve se atentar para que os instrumentos estejam sempre afinados e sintonizados com a partitura que se executa.

O Brasil já teve experiências com um forte dirigismo estatal na economia, como ocorreu com o tabelamento de preços de produtos essenciais ao consumo, inclusive com a sua limitação de aquisição por consumidor. Infelizmente, como se vem percebendo, a tendência jurisprudencial é a liberação generalizada e ilimitada dos lucros bancários por alguns tribunais, com algumas exceções. ${ }^{16}$ Neste caso, é de se questionar se o legislador não deveria impor limites razoáveis

${ }^{16}$ EMENTA: CÓDIGO DE DEFESA DO CONSUMIDOR. ART. 5ำ, XXXII, DA CB/88. ART. 170, V, DA CB/88. INSTITUIÇÕES FINANCEIRAS. SUJEIÇÃO DELAS AO CÓDIGO DE DEFESA DO CONSUMIDOR, EXCLUÍDAS DE SUA ABRANGÊNCIA A DEFINIÇÃO DO CUSTO DAS OPERAÇṌES ATIVAS E A REMUNERAÇÃO DAS OPERAÇÕES PASSIVAS PRATICADAS NA EXPLORAÇÃO DA INTERMEDIAÇÃO DE DINHEIRO

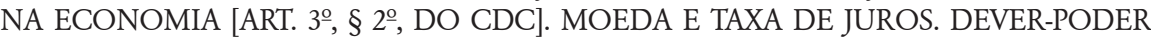
DO BANCO CENTRAL DO BRASIL. SUJEIÇÃO AO CÓDIGO CIVIL. 1. As instituições financeiras estão, todas elas, alcançadas pela incidência das normas veiculadas pelo Código de Defesa do Consumidor. 2. "Consumidor", para os efeitos do Código de Defesa do Consumidor, é toda pessoa física ou jurídica que utiliza, como destinatário final, atividade bancária, financeira e de crédito. 3. O preceito veiculado pelo art. 3ㅜㅡ, 
aos lucros das instituições financeiras e de crédito com maior comprometimento, apesar dos esforços praticados, como a delimitação do rol de tarifas possíveis de serem praticadas, dando maior transparência e clareza aos consumidores, tudo conforme as Resoluções do CMN n. 3.516, 3.517 e 3.518, e as Circulares do Banco Central n. 3.371 e 3.377. Não obstante a isso, percebe-se uma nítida tentativa do Governo Federal em não assumir uma disputa direta no sentido de limitar o lucro das instituições bancárias e de crédito, optando por adotar uma conduta de espera que a concorrência entre elas seja a melhor solução.

Então, como conciliar a ideia de lucro bancário com o instituto da lesão?

$\S 2^{2}$, do Código de Defesa do Consumidor deve ser interpretado em coerência com a Constituição, o que importa em que o custo das operações ativas e a remuneração das operações passivas praticadas por instituições financeiras na exploração da intermediação de dinheiro na economia estejam excluídas da sua abrangência. 4. Ao Conselho Monetário Nacional incumbe a fixação, desde a perspectiva macroeconômica, da taxa base de juros praticável no mercado financeiro. 5. O Banco Central do Brasil está vinculado pelo dever-poder de fiscalizar as instituições financeiras, em especial na estipulação contratual das taxas de juros por elas praticadas no desempenho da intermediação de dinheiro na economia. 6. Ação direta julgada improcedente, afastando-se a exegese que submete às normas do Código de Defesa do Consumidor [Lei n. 8.078/90] a definição do custo das operações ativas e da remuneração das operações passivas praticadas por instituições financeiras no desempenho da intermediação de dinheiro na economia, sem prejuízo do controle, pelo Banco Central do Brasil, e do controle e revisão, pelo Poder Judiciário, nos termos do disposto no Código Civil, em cada caso, de eventual abusividade, onerosidade excessiva ou outras distorções na composição contratual da taxa de juros. ART. 192, DA CB/88. NORMA-OBJETIVO. EXIGENNCIA DE LEI COMPLEMENTAR EXCLUSIVAMENTE PARA A REGULAMENTAÇÃO DO SISTEMA FINANCEIRO. 7. O preceito veiculado pelo art. 192 da Constituição do Brasil consubstancia norma-objetivo que estabelece os fins a serem perseguidos pelo sistema financeiro nacional, a promoção do desenvolvimento equilibrado do País e a realização dos interesses da coletividade. 8. A exigência de lei complementar veiculada pelo art. 192 da Constituição abrange exclusivamente a regulamentação da estrutura do sistema financeiro. CONSELHO MONETÁRIO NACIONAL. ART. 4으, VIII, DA LEI N. 4.595/64. CAPACIDADE NORMATIVA ATINENTE À CONSTITUIÇÃO, FUNCIONAMENTO E FISCALIZAÇÃO DAS INSTITUIÇÕES FINANCEIRAS. ILEGALIDADE DE RESOLUÇÕES QUE EXCEDEM ESSA MATÉRIA. 9. O Conselho Monetário Nacional é titular de capacidade normativa - a chamada capacidade normativa de conjuntura - no exercício da qual lhe incumbe regular, além da constituição e fiscalização, o funcionamento das instituições financeiras, isto é, o desempenho de suas atividades no plano do sistema financeiro. 10. Tudo o quanto exceda esse desempenho não pode ser objeto de regulação por ato normativo produzido pelo Conselho Monetário Nacional. 11. A produção de atos normativos pelo Conselho Monetário Nacional, quando não respeitem ao funcionamento das instituições financeiras, é abusiva, consubstanciando afronta à legalidade. (STF. Tribunal Pleno. ADI 2591, Rel.: Min. Carlos Velloso, Rel. p/ Acórdão: Min. Eros Grau, julgado em 07/06/2006, DJ 29-09-2006). 
Note-se que a espécie aí tratada é da lesão usurária. Mesmo que as práticas destas instituições de crédito são evidentemente desproporcionais, ou seja, presente o elemento objetivo da lesão, nem sempre se pode comprovar o elemento subjetivo para a configuração da lesão e o pleito da rescindibilidade contratual.

\subsection{Do Momento de Apreciação da Lesão}

Dispõe o $§ 1^{\circ}$ do art. 157 que a desproporção das prestações será apreciada segundo os valores vigentes ao tempo em que foi celebrado, seguindo uma tradição de vários outros códigos, como percebido em tópico anterior.

Uma indagação pertinente é no sentido de se a lesão poderá ser apreciável no momento anterior da celebração da promessa contratual, isto é, no contrato preliminar. Entende-se que não, sendo apenas possível sua constatação na formação do contrato, eis que se constatada a existência dos elementos objetivo e subjetivo, suscitados pelo caput do art. 157, há justo motivo para a sua não celebração, não acarretando qualquer discussão acerca de eventual responsabilidade civil daí advinda.

De observar que este $\S 1^{\circ}$ dispõe apenas do elemento objetivo, e não do elemento subjetivo. Assim, se a premente necessidade existir no momento da celebração do contrato preliminar, ou seja, da transação econômica, mas não no momento da celebração do contrato, isto é, da operação econômica, não haverá lesão, eis que seria possível seu desfazimento ou justa recusa de sua contratação. Haverá, portanto, a convalidação do ato.

\subsection{Do Desaparecimento posterior da Desproporção entre as Prestações ou do Reequilíbrio Automático da Avença}

A desproporção entre as prestações pode desaparecer em momento posterior à celebração do contrato. A controvérsia reside em saber se ocorrendo isto a lesão desaparecerá, tornando o contrato inatacável ou ainda discutível. O que se busca compreender, destarte, é a possibilidade ou não de um reequilíbrio automático da avença.

O art. 1448, parte 3, do Código Civil da Itália determina que "a lesão deve perdurar até o tempo em que a ação é proposta”. ${ }^{17}$ Também o art. 954, item 3, do Código Civil Argentino dispõe a este respeito: "Os cálculos deverão se fazer segundo valores ao tempo do ato e a desproporção deverá subsistir no momento da ação" ${ }^{18}$

${ }^{17}$ La lesione deve perdurare fino al tempo in cui la domanda è proposta. 
Saliente-se que o desequilíbrio objetivo pode desaparecer em momento posterior pelos seguintes motivos, além da imposição judicial:

a) pela vontade das partes;

b) pela oscilação do valor das prestações.

O primeiro motivo se dá de maneira óbvia, pela transação entre os contraentes com o fim ou de desfazimento do objeto ou com a sua manutenção, oferecendo suplemento suficiente ou com a redução do proveito. Ocorrendo esta hipótese, é possível que a lesão seja afastada desde que restabelecido o equilíbrio objetivo contratual.

Pelo segundo motivo, a oscilação do valor das prestações pode decorrer naturalmente tanto pela desvalorização da prestação considerada de maior valor como pela valorização daquela de menor valor, ou ambas. Caio Mário da Silva Pereira entende que havendo isto o lesado não pode alegar lesão, e requerer consequentemente sua anulabilidade, pois não mais existe a desvantagem, neste sentido:

$\mathrm{Na}$ verdade, desde sua origem o instituto se apresenta como filho da eqüidade, e seu objetivo tem sido a comutatividade. Ora, é desconforme à equitatividade e escapa à equivalência das prestações o poder uma das partes acionar a outra por lesão, se no momento em que ingressa em juízo as prestações já se equipararam, ainda que por motivo independente da vontade das partes. Obviamente será injustiça contratual, e, pois, infração da equidade, que o contratante possa alegar uma desvantagem quando, no momento em que a invoca, tal dano já é inexistente (PEREIRA, 1994, p. 176).

Discordando de tais alegações, há quem as fundamente no próprio direito obrigacional, visto que a hipótese seria equivalente à do art. 234 e 492, ambos do Código Civil ${ }^{19}$ (CARDOSO, 2008, p. 254), ou seja, equiparado ao perecimento do objeto. Apenas para corrigir esta imprecisão, tratar-se-ia na verdade de prestação equivalente a deterioração ou perecimento não de bem em obrigação de restituir, e não em obrigação de dar coisa certa. A regra a ser aplicável, então, seria a contida nos arts. 239 e 240 do Código Civil, in verbis:

${ }^{18}$ Los cálculos deberán hacerse según valores al tiempo del acto y la desproporción deberá subsistir en el momento de la demanda.

${ }^{19}$ Art. 234. Se, no caso do artigo antecedente, a coisa se perder, sem culpa do devedor, antes da tradição, ou pendente a condição suspensiva, fica resolvida a obrigação para ambas as partes; se a perda resultar de culpa do devedor, responderá este pelo equivalente e mais perdas e danos.

Art. 492. Até o momento da tradição, os riscos da coisa correm por conta do vendedor, e os do preço por conta do comprador. 
Art. 239. Se a coisa se perder por culpa do devedor, responderá este pelo equivalente, mais perdas e danos.

Art. 240. Se a coisa restituível se deteriorar sem culpa do devedor, recebê-la-á o credor, tal qual se ache, sem direito a indenização; se por culpa do devedor, observar-se-á o disposto no art. 239.

Acrescenta-se a este entendimento, a equiparação da lesão com o instituto correlato do enriquecimento sem causa. Não se pode deixar de comparar, então, com a hipótese prevista da ausência superveniente da causa do enriquecimento, contida na disposição do art. 885 do Código Civil, pois: "A restituição é devida, não só quando não tenha havido causa que justifique o enriquecimento, mas também se esta deixou de existir".

Como resolver, então, tal questão? Entende-se que o que se busca com a vedação da lesão é a justiça contratual, com o equilíbrio das prestações. Se a viúva que vendeu a casa alegar lesão e, posteriormente, este imóvel sofre desabamento por causas naturais, não há o que se pleitear, visto que mesmo que se o contrato fosse rescindido e retornado ao status quo ante, o objeto mesmo assim pereceria. Seria até pior para o lesado, se aquele que se beneficiou com o contrato concordasse com a ação proposta e exigisse a devolução daquilo que pagou, se o bem perecesse supervenientemente à propositura da ação de rescindibilidade. Haveria muito mais prejuízo ao lesado, outrossim, possibilitando o favorecimento do explorador ou do beneficiado com o contrato eivado de lesão.

Compreende-se que a solução mais justa ao caso seria, portanto, a impossibilidade de discussão da lesão se houvesse o restabelecimento superveniente do equilíbrio contratual por motivos ou acontecimentos alheios às partes, restaurando, desta forma, a equidade e eliminando o defeito.

\subsubsection{Lesão superveniente}

Ante a grande similitude que a lesão contratual possui com a onerosidade excessiva, é imperioso algumas considerações sobre o assunto. É fácil a constatação de que ambos institutos guardam o ponto em comum de objetivar a manutenção do equilíbrio contratual. Contudo, além de seus elementos específicos, a primeira se concentra no momento da formação do contrato, enquanto a segunda se forma a partir de um contrato avençado de maneira ainda equilibrada, e só depois é que se desconstrói tal equilíbrio.

A onerosidade superveniente encontra diferenças elementares entre a disposição do atual Código Civil e a do Código de Defesa do Consumidor. Nesta legislação consumerista, o art. $6^{\circ}$, inciso V e o art. 51, inciso IV e $\S 1^{\circ}$, inciso III, não exigem que os acontecimentos supervenientes modificadores da 
situação existente à época da celebração dos contratos sejam imprevistos e nem imprevisíveis. Basta que onerem excessivamente o consumidor para ensejar a revisão do contrato. Não se está, neste caso, diante da teoria da imprevisão, que exige, dentre outros elementos, ${ }^{20} \mathrm{a}$ imprevisibilidade dos acontecimentos e a extrema vantagem para o credor. Estes elementos encontram-se, todavia, no art. 478 do Código Civil, que faculta a resolução dos contratos por onerosidade excessiva, se não modificados a patamares equitativos (de acordo com o art. 479 do Código Civil), nos seguintes termos:

Art. 478. Nos contratos de execução continuada ou diferida, se a prestação de uma das partes se tornar excessivamente onerosa, com extrema vantagem para a outra, em virtude de acontecimentos extraordinários e imprevisíveis, poderá o devedor pedir a resolução do contrato. Os efeitos da sentença que a decretar retroagirão à data da citação. ${ }^{21}$

Art. 479. A resolução poderá ser evitada, oferecendo-se o réu a modificar eqüitativamente as condições do contrato.

Observado, assim, uma relativa simetria entre os institutos, comprovando o espírito do Código Civil, em evitar o desequilíbrio contratual.

\section{CONCLUSÕES}

O Código Civil de 2002 contempla o instituo da lesão contratual em seu art. 157 e possui dois elementos essenciais para a sua configuração: um objetivo, que é uma prestação manifestamente desproporcional ao valor da prestação oposta, e outro subjetivo, que é ou a premente necessidade ou a inexperiência de quem contrata.

O valor da prestação oposta deve ser não o seu preço justo, mas o seu valor de mercado, desde que as condições do mercado estejam em situação

${ }^{20}$ Para um mais completo esclarecimento sobre a teoria da imprevisão, recomenda-se a obra de Nelson Borges, A Teoria da Imprevisão no Direito Civil e no Processo Civil. São Paulo: Malheiros, 2002.

${ }^{21}$ Entretanto o Projeto de Lei n. 3.619/2008, do Sr. Dep. Fed. Carlos Bezerra, apresenta a seguinte proposta de alteração da redação do art. 478 do Código Civil: "Nos contratos de execução continuada ou diferida, se a prestação de uma das partes se tornar excessivamente onerosa, com extrema vantagem para a outra, em virtude de acontecimentos extraordinários poderá o devedor pedir a resolução do contrato. Os efeitos da sentença que a decretar retroagirão à data da citação”. De nossa parte acreditamos ser merecedor de aplausos tal iniciativa, vez que se adéqua à linha de entendimento do Código de Defesa do Consumidor (arts. 6으, V, e 51, IV e $\S 1$, III). Segundo a própria justificativa do projeto, "Desnecessário, pois, que o fator de desequilíbrio, ocorrente durante o cumprimento do contrato, seja previsível ou não. Tem-se pois, que ocorrido um evento extraordinário que torne insuportável a contraprestação, impõe-se a revisão contratual”. 
equilibrada, na medida do possível. Tolera-se, assim, razoável margem de erro na determinação do preço de mercado e isso já impõe, por si só, a aceitação de razoáveis diferenças. Desta forma, nem toda desproporção interessa ao Direito e nem qualquer divergência de valor entre os bens de mesma natureza ou equivalentes acarreta a lesão.

De acordo com as diretrizes pós-positivistas e com a tendência dos códigos mais modernos que recepcionam o instituto da lesão, não se pode haver um parâmetro rígido para a configuração da desproporção entre as prestações.

A manifesta desproporção na prestação, para que ocorra a lesão, não depende somente das principais prestações estipuladas no contrato, mas de todo o seu conjunto, inclusive das acessórias e também nos benefícios patrimoniais desmesurados, excessivos, ainda que as prestações em si possam parecer, em princípio, equilibradas.

O magistrado deverá utilizar o seu agir prudencial na apreciação do elemento objetivo da lesão contratual. É por meio de sua experiência (inclusive de vida) que poderá auferir a existência ou não do instituto lesivo no contrato em análise em cada caso concreto de acordo com as circunstâncias percebidas e apresentadas pelas partes. Não há uma fórmula exata para sua apreciação, considerada a ausência de tarifação da lesão, critério este também adotado pela legislação de vários outros países. Agiu bem, portanto, o legislador pátrio em não engessar a caracterização lesiva com determinada porcentagem, possibilitando, destarte, a adequação do caso concreto naquilo considerado justo pelo juiz segundo os critérios extra-jurídicos porventura existentes e também de acordo com as exigências locais.

O lucro da atividade negocial não deve ser considerado como uma manifesta desproporção das prestações opostas, vez que aquele não comporta limites, segundo o sistema capitalista. Contudo, deve-se evitar situações anormais no mercado (monopólios, oligopólios e formação de cartéis) com a ausência de dirigismo estatal nos mais diversos setores da economia e situações de evidente exploração nas relações jurídicas.

Dispõe o § 1ำ do art. 157 que a desproporção das prestações será apreciada segundo os valores vigentes ao tempo em que foi celebrado, seguindo uma tradição de vários outros códigos.

A lesão não poderá ser apreciável no momento da celebração da promessa contratual, isto é, no contrato preliminar, porque é apenas possível a sua constatação na formação do contrato, eis que se constatada a existência dos elementos objetivo e subjetivo, suscitados pelo caput do art. 157, há justo motivo para a sua não celebração, não acarretando qualquer discussão acerca de eventual responsabilidade civil daí advinda. 
O desequilíbrio objetivo pode desaparecer em momento posterior pelos seguintes motivos, além da imposição judicial:

a) pela vontade das partes;

b) pela oscilação do valor das prestações.

Compreende-se que a solução mais justa em caso de desaparecimento posterior da desproporção entre as prestações ou do reequilíbrio automático da avença seria a impossibilidade de discussão da lesão se houvessem motivos ou acontecimentos alheios à vontade das partes, restaurando, desta forma, a eqüidade e eliminando o defeito.

A grande similitude que a lesão contratual guarda com a onerosidade excessiva é de que ambos institutos têm como ponto em comum objetivar a manutenção do equilíbrio contratual. Contudo, além de seus elementos específicos, a primeira se concentra no momento da formação do contrato, enquanto a segunda se forma a partir de um contrato avençado de maneira ainda equilibrada, e só depois é que se desconstrói tal equilíbrio.

\section{REFERÊNCIAS}

BECKER, Anelise. Teoria geral da lesão nos contratos. São Paulo: Saraiva, 2000. CARDOSO, Vladimir Mucury. Revisão contratual e lesão. Rio de Janeiro: Renovar, 2008.

DWORKIN, Ronald. Levando os direitos a sério. Tradução de Nélson Boeira. São Paulo: Martins Fontes: 2002.

GAGLIANO, Pablo Stolze; PAMPLONA FILHO, Rodolfo. Novo curso de Direito Civil. São Paulo: Saraiva, 2003. v. 1.

LISBOA, Roberto Senise. Manual de Direito Civil. Teoria Geral do Direito Civil. São Paulo: Saraiva, 2009.

NADER, Paulo. Introdução ao estudo do Direito. Rio de Janeiro: Forense, 1995. PEREIRA, Caio Mário da Silva. Lesão nos contratos. 6. ed. Rio de Janeiro: Forense, 1994.

RECASÉNS SICHES, Luís. Tratado general de filosofia del Derecho. México: Ed. Porrua, 1975.

RUGGIERO, Roberto de. Instituições de Direito Civil: introdução e parte geral: direito das pessoas. São Paulo: Saraiva, 1971. v. 1. 
TARTUCE, Flávio. Direito Civil, 1: lei de introdução e parte geral. São Paulo: Método, 2008.

TOMASZEWSKI, Adauto de Almeida (Org.). Lições fundamentais de direito: negócios jurídicos. Londrina: [o autor], 2006. v. 2.

et al. Afinal de contas, quanto é lesão? Rev. Ciênc. Jur. Soc. Unipar, Umuarama, v. 8, n. 1, p. 5-16, jan./jun. 2005. Disponível em: http://revistas. unipar.br/juridica/article/view/1338/1190. Acesso em: 26 mar. 2009.

VENOSA, Ś́lvio de Salvo. Direito Civil - Parte Geral. São Paulo: Atlas, 2007.

VIGO, Rodolfo Luis. Interpretação jurídica: do modelo juspositivista-legalista do século XIX às novas perspectivas. Tradução de Susana Elena Dalle Mura. São Paulo: Editora Revista dos Tribunais, 2005.

Artigo recebido em 20/09/09 e aceito em 25/09/09 